\section{Entry Pathways of UV Filters from Sunscreens to Swiss Lakes}

Marianne E. Balmer ${ }^{\star}$, Hans-Rudolf Buser, and Thomas Poiger

${ }^{*}$ Correspondence: Dr. M.E. Balmer, Agroscope FAW Wädenswil, Swiss Federal Research Station for Horticulture, P.O. Box 185, CH-8820 Wädenswil

Tel.: +41 4478362 66, Fax: +41 4478364 39, E-Mail: marianne.balmer@faw.admin.ch

Keywords: Chemical marker for domestic wastewater - 4-Methylbenzylidene camphor · Methyl triclosan · Surface waters

Organic UV filters, compounds which absorb ultraviolet light, are used in various personal care products such as shampoos, body lotions or lipsticks and, of course, in considerable amounts in sunscreen products. Some years ago, studies indicating that UV filters may be endocrine disruptors raised public concern. Particularly 4methylbenzylidene camphor (4-MBC), a frequently used UV filter, was discussed in newspapers and consumer magazines.

The rather lipophilic 4-MBC was found in small concentrations in various lakes. Its presence in treated wastewater clearly indicated that this 'indirect' input pathway does contribute to some extent to the load of this compound in surface waters. Nevertheless, 'direct inputs' from recreational activities such as swimming and bathing in lakes and rivers may also occur. Another lipophilic compound, methyl triclosan, was used to investigate the relative importance of such direct inputs.

Methyl triclosan, a transformation product of the widely used bactericide triclosan, is formed in small amounts in wastewater treatment plants and emitted to surface waters with the effluent. Its concentration is expected to be directly linked to the population living in the catchment area of a lake and the compound is considered as a suitable chemical marker for the burden of domestic wastewater to a lake. In fact, the concentration of methyl triclosan was highest in Greifensee, the lake with the largest population relative to its water throughflow, whereas concentrations were lower in Zürichsee. In Hüttnersee, a small lake that receives no wastewater inputs, methyl triclosan was not detected. In contrast, the concentrations of the UV filter 4-MBC, measured in summer 2002, were highest in Hüttnersee and higher in Zürichsee than in Greifensee.

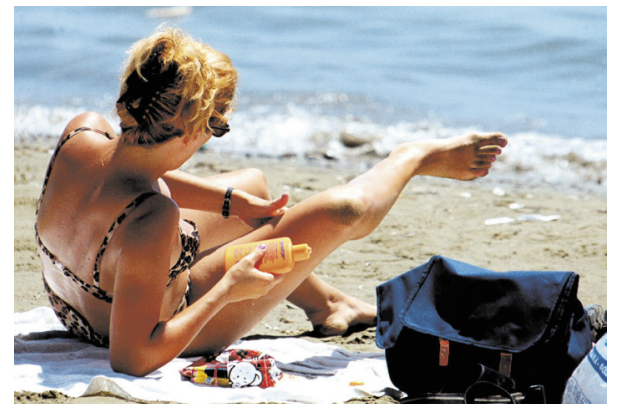

Organic UV filters from sunscreen products may enter surface waters as 'indirect inputs' via wastewater treatment plants or as 'direct inputs' from swimming and bathing in lakes and rivers. Photo: Keystone/Philip Mark.
Thus, concentrations of 4-MBC appear to be linked to the use of these lakes as recreational and swimming areas. The fact that the concentrations of 4-MBC and the chemical marker methyl triclosan do not correlate at all indicates that wastewater is not the main source of the UV filter, but direct inputs from recreational activities to surface waters are important, at least during summer.

\section{Acknowledgements}

This project was supported by the Swiss Federal Agency for the Environment, Forests and Landscape (BUWAL).

Received: December 16, 2005

\section{References}

M.E. Balmer, H.R. Buser, M.D. Müller, T. Poiger, Environ. Sci. Technol. 2005, 39, 953 .

M.E. Balmer, T. Poiger, C. Droz, K. Romanin, P.A. Bergqvist, M.D. Müller, H.R. Buser, Environ. Sci. Technol. 2004, 38, 390.

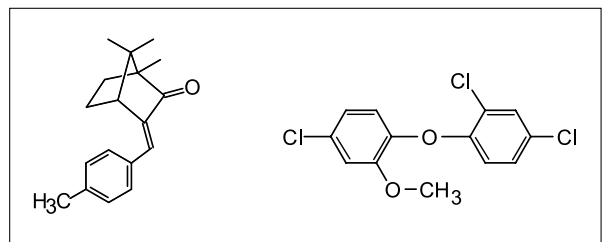

Chemical structures of the UV filter 4methylbenzylidene camphor (left) and the chemical marker methyl triclosan (right)

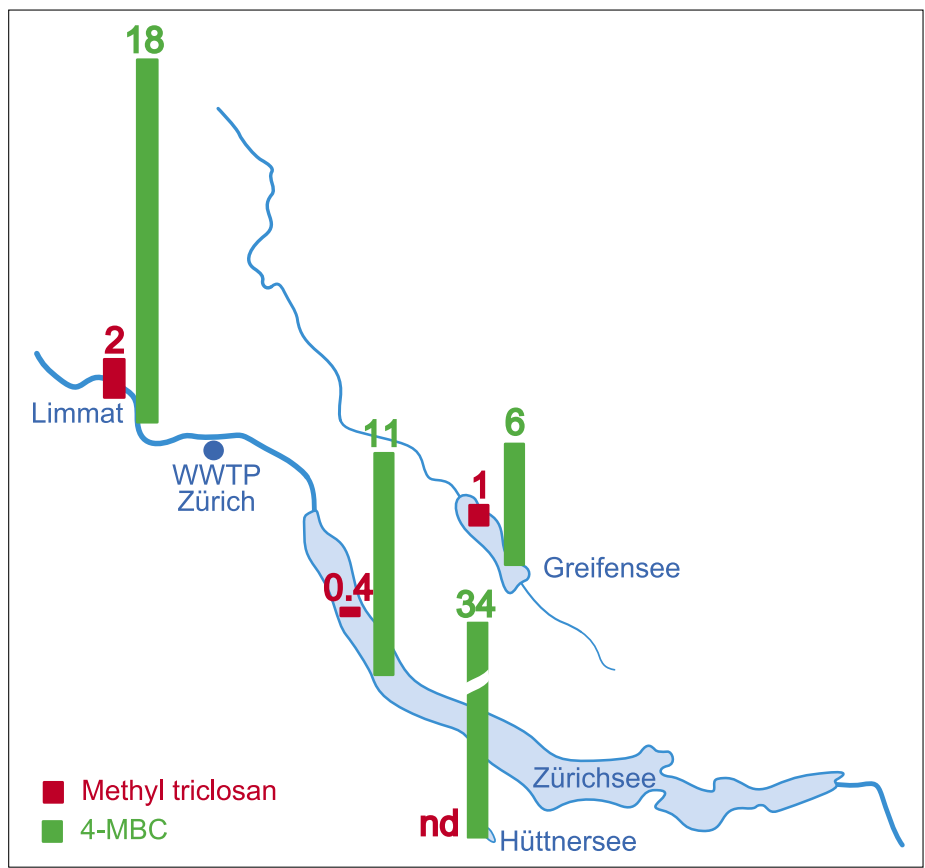

Concentrations of 4-MBC and methyl triclosan in three lakes and the river Limmat in summer 2002, suggesting significant direct inputs of the UV filter from recreational activities to Hüttnersee and Zürichsee. The numbers indicate the concentrations in $\mathrm{ng} \mathrm{I}^{-1}$ as estimated from the analysis of SPMDs (semipermeable membrane devices) which were used for passive sampling of surface waters (nd: not detected, $<0.02 \mathrm{ng} \mathrm{l}^{-1}$ ). 